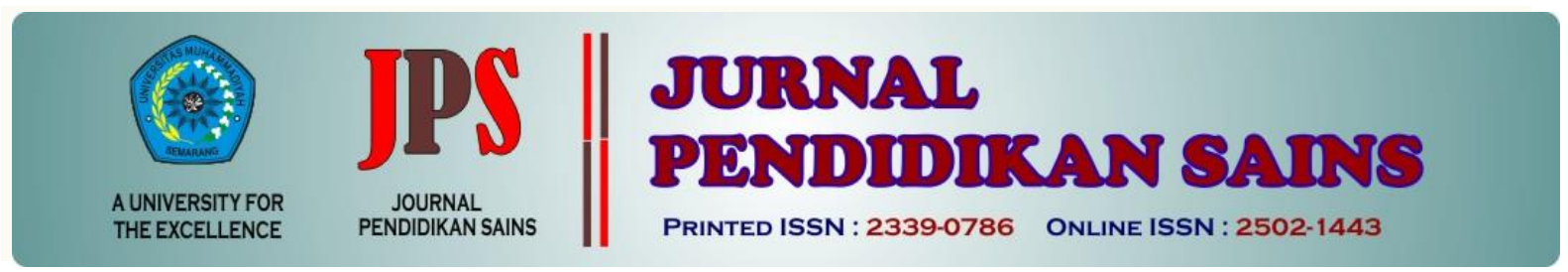

http://jurnal.unimus.ac.id/index.php/JPKIMIA

\title{
KAJIAN LITERATUR: MODEL MENTAL DAN METODE EVALUASINYA
}

\author{
Oleh: \\ Rian Priyadi $^{1}{ }^{*}$, Markus Diantoro $^{1}$, Parno $^{1}$ \\ ${ }^{1}$ Pendidikan Fisika- Pascasarjana Universitas Negeri Malang
}

\begin{tabular}{|c|c|c|}
\hline Article hist & & Abstract \\
\hline Submission & :2018-09-22 & \multirow{5}{*}{$\begin{array}{l}\text { Mental models is an ability that must be possessed by students, so it is } \\
\text { necessary to do a meaningful evaluation as a basis for developing } \\
\text { students' mental models. However, in Indonesia research on the field } \\
\text { of mental models is rarely done because of several factors, one of } \\
\text { which is a lack of reference methods that can be used as an evaluation } \\
\text { tool. The purpose of this article is to convey methods that can be used } \\
\text { to evaluate mental models derived from published articles. The results } \\
\text { of our study provide choices of methods that can be used, namely the } \\
\text { AC-SMM, SSI, SMD and PDE methods. }\end{array}$} \\
\hline Revised & :2018-10-14 & \\
\hline Accepted & : 2018-11-05 & \\
\hline \multicolumn{2}{|l|}{ Keyword: } & \\
\hline \multicolumn{2}{|c|}{$\begin{array}{l}\text { Kata Kunci: Kajian } \\
\text { Literatur, Model Mental, } \\
\text { Metode Evaluasi }\end{array}$} & \\
\hline
\end{tabular}

\section{Pendahuluan}

Ilmu sains terbagi menjadi tiga dimensi yakni dimensi makroskopik, mikroskopik, dan simbolik. Dimensi makroskopik mengkaji ilmu sains menurut konsep-konsep sains yang umum digunakan dalam memahami suatu ilmu. Dimensi mikroskopik mengkaji ilmu secara dimensi yang lebih kecil, misalnya atom-atom dan molekul penyusun suatu bahan maupun zat. Sedangkan dimensi simbolik digunakan untuk menerjemahkan konsep ilmu dengan menggunakan simbol-simbol maupun persamaan atau rumus-rumus (Jansoon et al., 2009; Kurnaz \& Emen, 2014). Pemahaman pada dimensi mikroskopik sangat membantu siswa dalam memahami ilmu sains pada dimensi lainnya, sehingga penting bagi siswa untuk membangun pemahaman pada dimensi mikroskopik (Albaiti et al., 2016).
Pemahaman dalam ketiga dimensi ini dapat dibangun secara bersamaan, cara ini sering disebut sebagai model mental. Model mental merupakan bentuk representasi dari diri setiap siswa ketika memahami suatu konsep ilmu (Albaiti et al., 2016; Haili et al., 2017; Kara \& Ertürk, 2015). Penelitian model mental lebih lanjut berada pada kajian psikologi kognitif yang digunakan untuk mempelajari bagaimana manusia belajar, mengingat (Rook, 2013; Sternberg, 2009), mempelajari proses mental (Docktor \& Mestre, 2014) dan mencari hubungan sistematis antara perilaku dan kognisi (Pitt, 2017).

Penelitian model mental saat ini telah berkembang pesat pada kajian ilmu sains. Namun, penelitian model mental pada bidang sains di Indonesia masih jarang dilakukan terutama pada kajian ilmu fisika. Hal ini terlihat dari masih terbatasnya hasil penelitian yang

*Corresponding Author:

$\begin{array}{ll}\text { Nama } & \text { : Rian Priyadi } \\ \text { Lembaga } & \text { : Pendidikan Fisika-Pascasarjana, Universitas Negeri Malang } \\ \text { Email } & \text { : rianpriyadi94@gmail.com }\end{array}$ 
telah dipublikasikan dalam jurnal maupun karya tulis lainnya. Padahal model mental merupakan salah satu kemampuan dasar yang harus dimiliki oleh siswa (Jansoon et al., 2009; Khemlani et al., 2014; Kurnaz \& Eksi, 2015; Kurnaz \& Emen, 2014). Kurangnya penelitian ini dapat disebabkan oleh beberapa hal, salah satunya dikarenakan minimnya referensi metode yang dapat digunakan untuk melakukan evaluasi model mental. Kajian pada artikel ini kami akan membahas beberapa metode evaluasi yang dapat digunakan untuk mengevaluasi model mental.

\section{Metode Penelitian}

Penelitian ini merupakan penelitian analisis konten, data-data yang disajikan berupa data-data hasil penelitian pada bidang model mental. Data ini dikumpulkan dari artikelartikel yang membahas model mental pada bidang sains beserta alat evaluasinya yang telah dipublikasikan

\section{Hasil Penelitian dan Pembahasan}

Berdasarkan hasil kajian pada artikelartikel yang telah dipublikasikan, kami merangkum metode-metode evaluasi yang sering digunakan beserta indikator-indikator yang dapat memudahkan pengguna dalam mengevaluasi model mental siswa. Temuan metode evaluasi yang kami temukan disajikan pada Tabel 1 .

Tabel 1. Metode Evaluasi Model Mental

\begin{tabular}{ccl}
\hline No & Metode Evaluasi & \multicolumn{1}{c}{ Keterangan } \\
\hline 1 & AC-SMM & $\begin{array}{l}\text { Analysis Constructed } \\
\text { Shared Mental Model }\end{array}$ \\
\hline 2 & SSI & $\begin{array}{l}\text { Scientific, Synthetic and } \\
\text { Initial }\end{array}$ \\
\hline 3 & SMD & $\begin{array}{l}\text { Surface, Matching, and } \\
\text { Deep Structure }\end{array}$ \\
\hline 4 & PDE & $\begin{array}{l}\text { Practical, Descriptive } \\
\text { and Explicative }\end{array}$ \\
\hline
\end{tabular}

Informasi model mental siswa dapat dilakukan dengan melaukan evaluasi terhadap kemamuan siswa. Evaluasi ini dapat dilakukan dengan mengevaluasi konsep yang dibangun siswa dan juga dapat dilakukan menggunakan soal-soal yang dapat mengukur kemampuan siswa (Corpuz \& Rebello, 2011; Johnson-Laird,
2013). Penggunanan soal-soal harus mewakili ketiga dimensi yang telah diuraikan sebelumnya yakni penggunakan konsep, prediksi dan pemecahan masalah menggunakan persamaan atau rumus. Selanjutnaya hasil yanng didapat dianalisis menggunakan metode-metode yang dijelaskan sebagai berikut.

\section{AC-SMM (Analysis Constructed Shared Mental Model)}

Metode AC-SMM awalnya dikenalkan oleh O'Connor, et al (2004) sebagai metode dalam menentukan kesamaan model mental yang dimiliki oleh siswa. Metode ini digunakan dengan cara membandingkan konsep yang dimiliki oleh siswa dengan konsep yang dihasilkan secara bersama oleh semua siswa (Johnson et al., 2006; Shute et al., 2009). Metode AC-SMM dilakukan dengan beberapa tahapan yang disajikan pada Tabel 2. Hasil analisis ini selanjutnya dibandingkan dengan hasil analisis sebelumnya untuk melihat konsistensi model mental yang dimiliki oleh setiap siswa.

Tabel 2. Metode Evaluasi Model Mental Menggunakan AC-SMM

\begin{tabular}{|c|c|}
\hline $\begin{array}{l}\text { Tahapan } \\
\text { ACSMM }\end{array}$ & Keterangan \\
\hline $\begin{array}{l}\text { Tahap } 1 \\
\text { Kesepakatan } \\
\text { bersama }\end{array}$ & $\begin{array}{l}\text { Proses analisis berfokus pada } \\
\text { penentuan berbagai komponen } \\
\text { konsep dan hubungan logis } \\
\text { setelah topik dihasilkan. }\end{array}$ \\
\hline $\begin{array}{l}\text { Tahap } 2 \\
\text { Model mental } \\
\text { individu }\end{array}$ & $\begin{array}{l}\text { Individu disiapkan untuk } \\
\text { membangun model mental } \\
\text { melalui pembuatan peta konsep } \\
\text { secara individu. }\end{array}$ \\
\hline $\begin{array}{l}\text { Tahap } 3 \\
\text { ICMM Coding }\end{array}$ & $\begin{array}{l}\text { Membandingkan dan mengukur } \\
\text { tingkat kesamaan konsep individu } \\
\text { dengan konsep yang dibuat secara } \\
\text { bersama antar individu. }\end{array}$ \\
\hline $\begin{array}{l}\text { Tahap } 4 \\
\text { Analisis } \\
\text { kesamaan }\end{array}$ & $\begin{array}{l}\text { Melakukan analisis data individu } \\
\text { untuk menentukan item apa saja } \\
\text { yang sama dengan individu } \\
\text { lainnya. }\end{array}$ \\
\hline $\begin{array}{l}\text { Tahap 5 } \\
\text { Konstruksi } \\
\text { AC-SMM }\end{array}$ & $\begin{array}{l}\text { Konstruksi ACSMM dibangun } \\
\text { dari data yang didapatkan pada } \\
\text { tahap analisis kesamaan. }\end{array}$ \\
\hline
\end{tabular}

Sumber: Johnson, et al (2006)

\section{SSI (Scientific, Synthetic and Initial)}

Metode ini dikembangkan oleh Abraham, et al (1994) sebagai pola terstruktur evaluasi konsep yang dimiliki oleh siswa. Namun 
metode yang diperkenalkan ini belum memiliki indikator secara spesifik. Selanjutnya metode ini dikembangkan oleh Kurnaz \& Eksi (2015) sehingga memudahkan dalam melakukan evaluasi model mental. Terdapat dua rubrik yang dikembangkan untuk membantu melakukan evaluasi model mental, yakni rubrik evaluasi secara deskriptif dan evaluasi visual. Rubrik yang digunakan untuk melakukan evaluasi deskriptif disajikan pada Tabel 3 dan rubrik evaluasi visual disajikan pada Tabel 4.

Tabel 3. Rubrik Evaluasi Secara Deskriptif dengan Metode SSI

\begin{tabular}{|c|c|c|}
\hline $\begin{array}{c}\text { Level } \\
\text { Pemahaman }\end{array}$ & Kode & Keterangan \\
\hline $\begin{array}{l}\text { Sound } \\
\text { Understanding } \\
(S U)\end{array}$ & 4 & $\begin{array}{l}\text { Jawaban yang berisi } \\
\text { semua komponen respon } \\
\text { yang diterima secara } \\
\text { ilmiah }\end{array}$ \\
\hline $\begin{array}{l}\text { Partial } \\
\text { Understanding } \\
(P U)\end{array}$ & 3 & $\begin{array}{l}\text { Jawaban yang berisi } \\
\text { beberapa komponen } \\
\text { respon yang diterima } \\
\text { secara ilmiah }\end{array}$ \\
\hline $\begin{array}{l}\text { Partial } \\
\text { Understanding } \\
\text { with Alternative } \\
\text { Conception } \\
(P U-A C)\end{array}$ & 2 & $\begin{array}{l}\text { Jawaban menunjukkan } \\
\text { bahwa konsep tersebut } \\
\text { dipahami tetapi juga } \\
\text { mengandung konsepsi } \\
\text { lainnya }\end{array}$ \\
\hline $\begin{array}{l}\text { Alternative } \\
\text { Conception } \\
(A C)\end{array}$ & 1 & $\begin{array}{l}\text { Jawaban yang salah } \\
\text { secara ilmiah dan berisi } \\
\text { informasi yang tidak } \\
\text { masuk akal atau tidak } \\
\text { benar }\end{array}$ \\
\hline $\begin{array}{l}\text { No } \\
\text { Understanding } \\
(N U)\end{array}$ & 0 & $\begin{array}{l}\text { Respon kosong, tidak } \\
\text { relevan atau tidak jelas }\end{array}$ \\
\hline
\end{tabular}

Sumber: Kurnaz \& Eksi (2015)

Tabel 4. Rubrik Evaluasi Secara Visual dengan Metode SSI

\begin{tabular}{|c|c|c|}
\hline $\begin{array}{c}\text { Level } \\
\text { Pemahaman }\end{array}$ & Kode & Keterangan \\
\hline $\begin{array}{l}\text { Correct } \\
\text { Depicting }(C D)\end{array}$ & 4 & $\begin{array}{l}\text { Jawaban mencerminkan } \\
\text { semua komponen } \\
\text { penggambaran saintifik }\end{array}$ \\
\hline $\begin{array}{l}\text { Partial Correct } \\
\text { Depicting } \\
(P C D)\end{array}$ & 3 & $\begin{array}{l}\text { Jawaban mencerminkan } \\
\text { beberapa komponen } \\
\text { penggambaran saintifik }\end{array}$ \\
\hline $\begin{array}{l}\text { Correct } \\
\text { Drawing } \\
\text { reflecting also } \\
\text { Non-scientific } \\
\text { Depicting (CD- } \\
\text { ND) }\end{array}$ & 2 & $\begin{array}{l}\text { Jawaban mencerminkan } \\
\text { saintifik atau saintifik } \\
\text { parsial tetapi juga } \\
\text { menggambarkan yang } \\
\text { bukan saintifik }\end{array}$ \\
\hline $\begin{array}{l}\text { Incorrect } \\
\text { Depicting (ID) }\end{array}$ & 1 & $\begin{array}{l}\text { Jawaban yang } \\
\text { mencerminkan } \\
\text { penggambaran } \\
\end{array}$ \\
\hline
\end{tabular}

sepenuhnya yang bukan saintifik

No Depicting $\quad 0 \quad$ Jawaban kosong

(ND)

Sumber: Kurnaz \& Eksi (2015)

Setelah jawaban siswa dievaluasi menggunakan rubrik evaluasi deskriptif dan evaluasi visual, selanjutnya siswa dikelompokkan berdasarkan kategori model mental yang disajikan pada Tabel 5 .

Tabel 5. Metode Evaluasi Model Mental Menggunakan SSI

\begin{tabular}{|c|c|c|}
\hline Kategori & Kriteria & $\begin{array}{c}\text { Level } \\
\text { Pemahaman }\end{array}$ \\
\hline Scientific & $\begin{array}{l}\text { Persepsi yang } \\
\text { bertepatan pada level } \\
3 \text { (PU atau PCD) atau } \\
\text { level } 4 \text { (SU atau CD) }\end{array}$ & {$\left[\begin{array}{lll}3 & 3 & 3 \\
4 & 4 & 4\end{array}\right]$} \\
\hline Synthetic & $\begin{array}{l}\text { Persepsi yang } \\
\text { sebagian bertepatan } \\
\text { atau tidak sesuai } \\
\text { dengan pengetahuan }\end{array}$ & $\begin{array}{c}\text { Semua } \\
\text { kemungkinan } \\
\text { lainnya }\end{array}$ \\
\hline Initial & $\begin{array}{l}\text { Persepsi yang tidak } \\
\text { sesuai dengan } \\
\text { pengetahuan. Jawaban } \\
\text { berada pada level } 0 \\
\text { (NU atau ND), atau } \\
\text { level } 1 \text { (AC atau ID) } \\
\text { atau level } 2 \text { (PU-AC } \\
\text { atau CD-ND) }\end{array}$ & {$\left[\begin{array}{lll}0 & 0 & 0 \\
1 & 1 & 1 \\
2 & 2 & 2\end{array}\right]$} \\
\hline
\end{tabular}

Sumber: Kurnaz \& Eksi (2015)

\section{SMD (Surface, Matching, and Deep Structure)}

Metode SMD dilakukan dengan cara menilai proses siswa dalam memecahkan masalah yang kompleks. Analisis ini menghasilkan tingkatan model mental siswa yang terdiri dari tiga tingkatan, yakni surface (permukaan), matching (pencocokan), dan deep (mendalam) (Ifenthaler et al., 2008).

Tingkatan surface dilakukan dengan menilai hubungan struktur dari kognitif eksternal yang dimiliki oleh siswa. Tingkatan matching menilai konsep yang bersifat kompleks yang digunakan sebagai kunci dalam penilaian proses belajar siswa. Tingkatan deep dinilai dengan kesamaan pemahaman siswa dengan pemahaman ahli, biasanya tingkatan deep diuji dengan pertanyaan yang bersifat prediktif atau menggunakan soal-soal yang berada pada dimensi mikroskopik. 
Indikator yang digunakan untuk melakukan evaluasi model mental menggunakan metode SMD disajikan pada Tabel 6.

Tabel 6. Metode Evaluasi Model Mental Menggunakan SMD

\begin{tabular}{ll}
\hline $\begin{array}{c}\text { Tahapan } \\
\text { SMD }\end{array}$ & \multicolumn{1}{c}{ Keterangan } \\
\hline Surface & $\begin{array}{l}\text { Mampu menjawab benar namun tidak } \\
\text { mampu memberikan alasan. }\end{array}$ \\
\hline Matching & $\begin{array}{l}\text { Mampu menjawab benar dengan } \\
\text { memberikan alasan yang benar. }\end{array}$ \\
\hline \multirow{2}{\text{Deep}}{} & $\begin{array}{l}\text { Mampu menjawab benar dengan } \\
\text { memberikan alasan yang benar, dan } \\
\text { dapat menjawab soal-soal prediktif. }\end{array}$ \\
\hline
\end{tabular}

Sumber: Ifenthaler, et al (2008)

\section{PDE (Practical, Descriptive and Explicative)}

Analisis model mental menggunakan metode PDE dikenalkan oleh Fazio, et al (2013). Metode PDE berisi jawaban siswa yang khas dari masing-masing jawaban siswa. Selanjutnya, rubrik yang dapat digunakan untuk mengevaluasi model mental dikembangkan oleh Fazio, et al (2017) yang berisikan indikator-indikator beserta kata kunci yang bisanya digunakan oleh siswa dalam memberikan jawaban atas pertanyaan yang diajukan. Indikator kategori model mental menggunakan metode PDE disajikan pada Table 7.

Tabel 7. Metode Evaluasi Model Mental Menggunakan PDE

\begin{tabular}{|c|c|c|}
\hline Kategori & Kriteria & Kata Kunci \\
\hline Practical & $\begin{array}{l}\text { Siswa } \\
\text { mencerminkan } \\
\text { makna } \\
\text { situasional } \\
\text { yang praktis, } \\
\text { dan } \\
\text { menggunakan } \\
\text { konteks lain } \\
\text { untuk } \\
\text { menjelaskan. }\end{array}$ & $\begin{array}{l}\text { - } \text { Menurut } \\
\text { pengalaman } \\
\text { saya... } \\
\text { - Dalam } \\
\text { kehidupan } \\
\text { nyata... } \\
\text { - Biasanya... } \\
\text { - Objek nyata... }\end{array}$ \\
\hline Descriptive & $\begin{array}{l}\text { Siswa } \\
\text { menjelaskan } \\
\text { dengan } \\
\text { menggunakan } \\
\text { variabel yang } \\
\text { relevan dan / } \\
\text { atau mengingat } \\
\text { dari } \\
\text { pengalaman, } \\
\text { (verbal, ikonik, } \\
\text { dan matematis) }\end{array}$ & $\begin{array}{l}\text { - Saya ingat itu... } \\
\text { - Saya } \\
\text { mempelajarinya } \\
\text {... } \\
\text { - Saya tahu itu... } \\
\text { - Rumus } \\
\text { mengatakan... }\end{array}$ \\
\hline
\end{tabular}

\begin{tabular}{lll}
\hline Kategori & \multicolumn{1}{c}{ Kriteria } & Kata Kunci \\
\hline & dan tidak & \\
& mampu & \\
& menjelaskan & \\
& hubungan & \\
& sebab akibat. & \\
\hline Explicative & Siswa & $\bullet$ Pergerakan \\
& mengusulkan & molekuler... \\
& solusi & $\bullet$ Mirip dengan... \\
& berdasarkan & $\bullet$ Interaksi... \\
& hubungan & \\
& sebab akibat & \\
& atau & \\
& memberikan & \\
& hipotesis & \\
& penjelasan. & \\
\hline
\end{tabular}

Sumber: Fazio, et al (2017)

Setiap metode evaluasi yang dikenalkan memiliki ciri khas yang berbeda dari pegaturan pengumpulan data, analisis data, dan konversi data. Perbedaan dari keempat metode tersebut dsajikan pada Tabel 8.

Tabel 8. Perbandingan Metode Evaluasi Model Mental

\begin{tabular}{|c|c|c|c|}
\hline Metode & $\begin{array}{c}\text { Pengumpulan } \\
\text { Data }\end{array}$ & $\begin{array}{c}\text { Analisis } \\
\text { Data }\end{array}$ & $\begin{array}{c}\text { Konversi } \\
\text { Data }\end{array}$ \\
\hline $\begin{array}{l}A C- \\
S M M\end{array}$ & Peta konsep & $\begin{array}{l}\text { Kualitatif } \\
\text { dengan } \\
\text { statistik } \\
\text { deskriptif }\end{array}$ & $\begin{array}{l}\text { Perbandi } \\
\text { ngan } \\
\text { yang } \\
\text { tidak } \\
\text { terbatas }\end{array}$ \\
\hline SSI & Bahasa natural & $\begin{array}{l}\text { Kualitatif: } \\
\text { analisis } \\
\text { dilakukan } \\
\text { mengguna } \\
\text { kan } \\
\text { instrumen } \\
\text { evaluasi }\end{array}$ & $\begin{array}{l}\text { Terbatas } \\
\text { pada tiga } \\
\text { kategori }\end{array}$ \\
\hline$S M D$ & $\begin{array}{l}\text { Peta konsep } \\
\text { dan bahasa } \\
\text { natural }\end{array}$ & $\begin{array}{l}\text { Kualitatif: } \\
\text { analisis } \\
\text { dilakukan } \\
\text { mengguna } \\
\text { kan } \\
\text { instrumen } \\
\text { evaluasi }\end{array}$ & $\begin{array}{l}\text { Terbatas } \\
\text { pada tiga } \\
\text { kategori }\end{array}$ \\
\hline$P D E$ & Bahasa natural & $\begin{array}{l}\text { Kualitatif: } \\
\text { analisis } \\
\text { dilakukan } \\
\text { mengguna } \\
\text { kan } \\
\text { instrumen } \\
\text { evaluasi }\end{array}$ & $\begin{array}{l}\text { Terbatas } \\
\text { pada tiga } \\
\text { kategori }\end{array}$ \\
\hline
\end{tabular}




\section{Simpulan dan Saran}

Simpulan

Keempat metode analisis model mental yang dapat digunakan untuk melakuakn penelitian model mental siswa dalam memahami konsep sains telah dijelaskan secara rinci. Keempat metode yang dapat digunakan yakni AC-SMM, SSI, SMD dan PDE. Metode AC-SMM dapat digunakan ketika ingin melihat hubunga model mental antara siswa dengan siswa lainnya. Sedangkan metode SSI, SMD, dan PDE digunakan ketika ingin mengelompokkan siswa dalam tingakatan model mental yang telah dijelaskan.

Saran

Setelah dijelaskan metode evaluasi model mental diharapkan penelitian-penelitian yang membahas model mental pada bidang sains di Indonesia mengalami kemajuan. Hal ini dikarenakan model mental merupakan salah satu kemampuan yang harus diungkap dari diri siswa untuk membanti proses belajar siswa

\section{Daftar Pustaka}

Abraham, M. R., Williamson, V. M., \& Westbrook, S. L. (1994). A Cross-Age Study of The Understanding of Five Chemistry Concepts. Journal of Research in Science Teaching, 31(2), 147-165. DOI:10.1002/tea.3660310206

Albaiti, Liliasari, \& Sumarna, O. (2016). The Study of Mental Model on N-HexaneMethanol Binary System (The Validation of Physical Chemistry Practicum Procedure). Jurnal Pendidikan IPA Indonesia, 5(1), 6-13. DOI:10.15294/jpii.v5i1.5783

Corpuz, E. D., \& Rebello, N. S. (2011). Investigating Students' Mental Models and Knowledge Construction of Microscopic Friction. II. Implications for Curriculum Design and Development. Physical Review Special Topics - Physics Education Research, 7, 020103. DOI:10.1103/PhysRevSTPER.7.020103

Docktor, J. L., \& Mestre, J. P. (2014). Synthesis of Discipline-based Education Research in Physics. Physical Review Special Topics - Physics Education Research,
10(2),

020119.

DOI:10.1103/PhysRevSTPER.10.020119

Fazio, C., Battaglia, O. R., \& Di Paola, B. (2013). Investigating The Quality of Mental Models Deployed by Undergraduate Engineering Students in Creating Explanations: The Case of Thermally Activated Phenomena. Physical Review Special Topics - Physics Education Research, 9(020101), 1-21. DOI:10.1103/PhysRevSTPER.9.020101

Fazio, C., Battaglia, O. R., \& SperandeoMineo, R. M. (2017). Quantitative and Qualitative Analysis of The Mental Models Deployed by Undergraduate Students in Explaining Thermally Activated Phenomena. Scientia in Educatione, 8(Special Issue), 151-164. Retrieved from www.scied.cz/index.php/scied/article/vie wFile/739/380

Haili, H., Maknun, J., \& Siahaan, P. (2017). Problem Solving Based Learning Model With Multiple Representations to Improve Student's Mental Modelling Ability on Physics. In AIP Conference Proceedings (Vol. 070004, pp. 1-7). America: AIP Publishing. DOI:10.1063/1.4995180

Ifenthaler, D., Pirnay-Dummer, P., \& Spector, J. M. (2008). Understanding Models for Learning and Instruction. New York: Springer Science \& Business Media, LLC.

Jansoon, N., Coll, R. K., \& Somsook, E. (2009). Understanding Mental Models of Dilution in Thai Students. International Journal of Environmental and Science Education, 4(2), 147-168. Retrieved from

http://www.ijese.net/makale_indir/1387

Johnson-Laird, P. N. (2013). Mental Models and Cognitive Change. Journal of Cognitive Psychology, 25(2), 131-138. DOI:10.1080/20445911.2012.759935

Johnson, T. E., O'Connor, D. L., PirnayDummer, P. N., Ifenthaler, D., Spector, J. M., \& Seel, N. (2006). Comparative Study of Mental Model Research Methods: Relationships Among ACSMM, SMD, MITOCAR \& DEEP Methodologies. In Proc. of the Second Int. Conference on Concept Mapping. 
(Vol. 1, pp. 87-94). San José, Costa Rica. Retrieved from http://eprint.ihmc.us/164/

Kara, S. B. K., \& Ertürk, A. (2015). Mental Models of the School Principals on Leadership. Procedia - Social and Behavioral Sciences, 174, 2145-2152. DOI:10.1016/j.sbspro.2015.02.014

Khemlani, S. S., Barbey, A. K., \& JohnsonLaird, P. N. (2014). Causal reasoning with mental models. Frontiers in Human Neuroscience, $\quad 8$ (October), $1-15$. DOI: $10.3389 /$ fnhum.2014.00849

Kurnaz, M. A., \& Eksi, C. (2015). An Analysis of High School Students' Mental Models of Solid Friction in Physics. Educational Sciences: Theory \& Practice, 15(3), 787795. DOI:10.12738/estp.2015.3.2526

Kurnaz, M. A., \& Emen, A. Y. (2014). Student Mental Models Related to Expansion and Contraction. Acta Didactica Napocensia, 7(1), 59-67.

O'Connor, D. L., Johnson, T. E., \& Khalil, M. K. (2004). Measuring Team Cognition: Concept Mapping Elicitation as a Means of Constructing Team Shared Mental Models in an Applied Setting. Proc. of the First Int. Conference on Concept Mapping, 1(2000), 487-494. Retrieved from http://eprint.ihmc.us/81/

Pitt, D. (2017). Mental Representation. In Stanford Encyclopedia of Philosophy (Spring 201). Stanford University: Metaphysics Research Lab. Retrieved from

https://plato.stanford.edu/archives/spr201

7/entries/mental-representation

Rook, L. (2013). Mental Models: A Robust Definition. The Learning Organization, 20(1), $38-47$. DOI: $10.1108 / 09696471311288519$

Shute, V. J., Jeong, A. C., Spector, J. M., Seel, N. M., \& Johnson, T. E. (2009). ModelBased Methods for Assessment, Learning, and Instruction: Innovative Educational Technology at Florida State University. In M. Orey, V. J. McClendon, \& R. M. Branch (Eds.), Educational Media and Technology Yearbook (Vol. 34, pp. 61-79). Boston, MA: Springer US. DOI:10.1007/978-0387-09675-9_5
Sternberg, R. J. (2009). Psikologi Kognitif. (T. Santoso, Ed.) (4th ed.). Yogyakarta: Pustaka Pelajar. 